\title{
Who Creates a Google Scholar Profile?
}

Hannah June Kim, Stanford University

Bernard Grofman, University of California, Irvine

ABSTRACT This article uses data collected from Google Scholar to identify characteristics of scholars who have chosen to create a Google Scholar profile. Among tenured and tenuretrack faculty with full-time appointments in PhD-granting political science departments, we find that only $43.7 \%$ have created a profile. However, among R1 faculty, young and early-career faculty are more likely to have Google Scholar profiles than those in older cohorts. Although subfield differences are largely nonexistent, there is a notably low proportion of theory faculty with profiles and a slightly higher proportion with profiles among methodologists. Moreover, within cohorts, those who are highly cited are more likely to have profiles than those who have low citation counts. We conclude by discussing implications of our findings, the increasing usage of Google Scholar and profiles, and the increasing importance of an online presence in the academy.

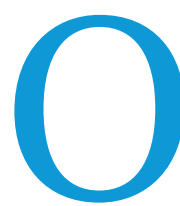

riginally created in 2004, Google Scholar provides access to journal articles, academic books, book chapters, and non-peer-reviewed materials. Google Scholar citation counts have been used in hiring and tenure decisions as a criterion of evaluation, and citation counts have increasingly been used to provide rankings of individual faculty in terms of their citation counts relative to others in their cohort or field (Kim and Grofman 2019; cf. Masuoka, Grofman, and Feld 2007) and in ranking departments in terms of the total or mean citation counts of their faculty (Peress 2018). However, as discussed in Chwe et al. (2017), and even more vociferously in online web postings, the use of citation counts for these purposes remains controversial. One issue concerns the degree to which Google Scholar coverage has defects (Samuels 2011; 2013), but the greatest controversy is about the use of citation counts as a metric for evaluating scholarly performance. We do not take a position regarding that controversy. Rather, we simply note the undisputed fact that because it is so easily accessed and so apparently comprehensive, Google Scholar has become the app of choice to quickly trace work on particular topics or to locate a scholar's publications, including books.

Access to authors' work is facilitated if they create a Google Scholar profile. To create a profile, a scholar first provides basic biographic information and then relevant publications. In addition to showing citations to each identified work, a scholar's total

Hannah June Kim (DD is a postdoctoral scholar at Stanford University's Walter H. Shorenstein Asia-Pacific Research Center. She can be reached at hkim1o@stanford.edu. Bernard Grofman (D) is Jack W. Peltason (Bren Foundation Endowed) Chair of Democracy Studies and Distinguished Professor of Political Science at the University of California, Irvine. He can be reached at bgrofman@uci.edu. citation count is automatically tabulated by the app. Scholars who want to increase exposure to their work have an incentive to create this profile.

Many scholars use Google Scholar profiles to find information but less than $45 \%$ have their own profile. The goal of this study is to identify characteristics of those scholars who have chosen to create a personal Google Scholar profile. To do the necessary matching of profiles and demographic, academic-rank, and field-of-interest information about profile creators, we limited the search to tenured and tenure-track faculty with full-time appointments in $\mathrm{PhD}$ granting political science departments. We then could take advantage of the data collected by Kim and Grofman (2019) for this set of scholars because it already contains the necessary information. Even among this restricted set of political scientists-who presumably have a strong incentive to create a Google Scholar profile because they are at research-oriented universities-only $43.7 \%$ created one (i.e., 1,654 who did versus 2,128 who did not).

This article examines how the creation of Google Scholar profiles for the faculty in the Kim and Grofman (KG) dataset is affected by rank and date of $\mathrm{PhD}$, subfield, gender, and citation count. Using this dataset, we might expect that older faculty are less likely than younger faculty to have a Google Scholar profile; highly cited faculty more likely than less-cited faculty; women less likely than men; or possible differences by subfield. We examine these expectations and discuss the implications of our findings.

First, we assess this question by rank (figure 1). There are no strong differences across faculty ranks in the likelihood of having a Google Scholar profile, with the exception of emeriti, of whom only $10 \%$ have profiles. However, although the differences are not as significant as we might have expected, younger faculty are more likely to have a Google Scholar profile than those in higher ranks: more than $55 \%$ of assistant professors maintain a profile. 


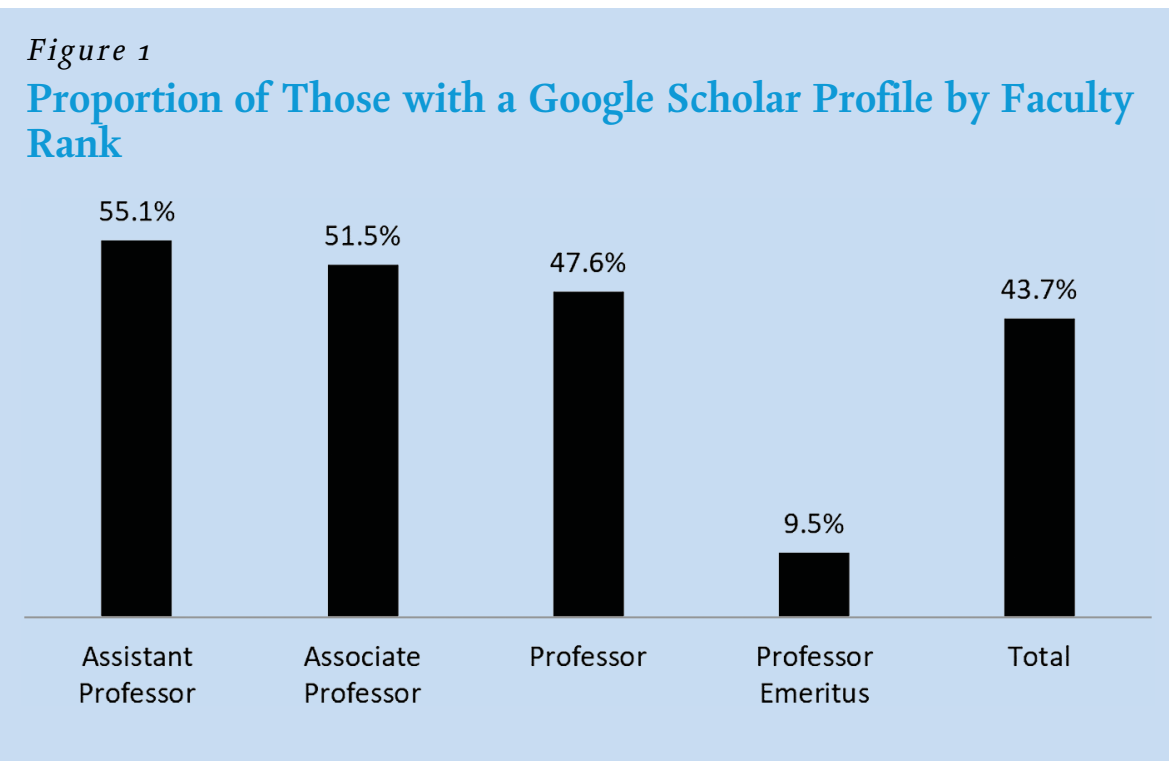

\section{Figure 2

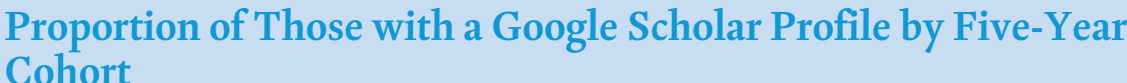

$100 \%$

$90 \%$

$80 \%$

$70 \%$

$60 \%$

$50 \%$

$40 \%$

$30 \%$

$20 \%$

$10 \%$

$0 \%$

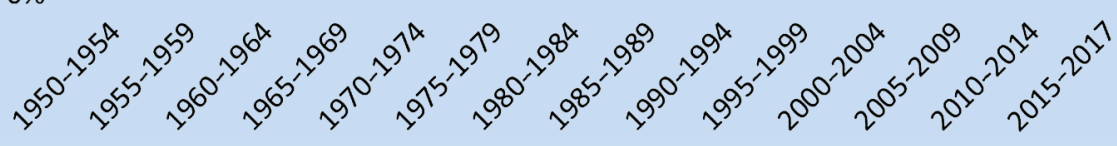

the pattern is near monotonic. We do not expect the one exception to monotonicity in this graph (i.e., the most recent cohort) to be lasting because we assume that some of those with very recent $\mathrm{PhDs}$ will create a Google Scholar profile when they have more publications and receive more citations.

Table 1 shows the same type of data as in figures 1 and 2 but by principal subfield.

Table 1 shows that between $43 \%$ and $55 \%$ of those in each subfield have a Google Scholar profile, with the notable exception of theory, which is only $24 \%$.

Figure 3 shows the same type of data as in figures 1 and 2 but by gender.

The figure shows that there is no substantively meaningful difference between female and male scholars in the likelihood of creating a Google Scholar profile and that female scholars are slightly more likely to have one. ${ }^{4}$

Figure 4 shows the same type of data as in figures 1, 2, and 3 but distinguishes among faculty by their citation count relative to others in their cohort. That is, for each cohort, the figure compares the proportion of those who have a Google Scholar profile among those in the top 25 of the cohort in terms of number of citations with those in the bottom 25 of the cohort regarding citations. ${ }^{5}$

We expect that, controlling for cohort effects, more-cited scholars are more likely to have a Google Scholar profile than lesscited scholars. Figure 4 demonstrates this because those in the top 25 of each cohort are much more likely to have a profile than those in the bottom 25. Although the ratio of the two percentages is greatest for some of the older cohorts, more than $95 \%$ in the top 25 of the $2000-2014$ cohort maintain a profile. We expect that the proportion with a profile will increase among the most-cited scholars in the most recent cohort as they become more professionally involved.
However, figure 1 may be misleading in that the ranks of full and associate professors show considerable variability in the date of the $\mathrm{PhD}$ of faculty in those ranks. Figure 2 shows the same type of data as in figure 1 but by five-year cohorts.

\section{SUMMARY OF RESULTS}

The figures and table show that when looking at those who have a Google Scholar profile and those who do not, among the set of those in the Kim and Grofman (2019) dataset and contrary

\section{Many scholars use Google Scholar profiles to find information but less than 45\% have their own profile.}

Figure 2 shows that those in more recent cohorts are much more likely to have a Google Scholar profile than those in older cohorts. More than half of those in the cohorts from 1995 to 2014 have a Google Scholar profile, whereas less than $10 \%$ of the stillteaching faculty with a PhD from 1950 to 1969 have a profile, and to our initial expectation, there are no real differences by gender. Similarly, there are few differences by subfield, with the notable exception of the low proportion of theory faculty who have a profile and the fact that having a profile is slightly more common among those who self-label as methodologists. 
Table 1

Proportion of Those with a Google Scholar Profile by Subfield

\begin{tabular}{lccc} 
Field & Google Scholar Profile & Total Cited Scholars & Proportion with a Profile \\
\hline American & 501 & 1,141 & $43.9 \%$ \\
\hline Comparative & 445 & 968 & $46.0 \%$ \\
\hline International Relations & 397 & 829 & $47.9 \%$ \\
\hline Methods & 81 & 148 & $54.7 \%$ \\
\hline Theory & 88 & 367 & $24.0 \%$ \\
\hline PP, PA, PL, PP & 142 & 329 & $43.2 \%$ \\
\hline
\end{tabular}

Notes: $\mathrm{PP}=$ public policy; $\mathrm{PA}=$ public administration; $\mathrm{PL}=$ public law; and $\mathrm{PP}=$ political psychology.

\section{Figure 3}

\section{Proportion of Those with a Google Scholar Profile by Gender}

$45.4 \%$

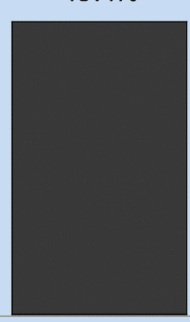

Female

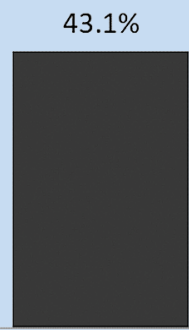

Male
However, as expected, with the exception of those recently starting in the discipline, younger cohorts are more likely to have a Google Scholar profile than older cohorts. Moreover, figure 4 shows that those who are highly cited relative to others in their cohort are more likely to have a profile than those who have fewer citation counts.

\section{WHAT DO THE GOOGLE SCHOLAR} PROFILE DATA IMPLY?

The Google Scholar profile data show that junior and early-career faculty are more likely to have a profile, political theorists are less likely to have a profile, and those with higher citation counts are more likely to have a profile.

\section{Junior and Early-Career Faculty Are More Likely to Have a Google Scholar Profile}

As Jensenius et al. (2018) pointed out, Google Scholar often is used to evaluate faculty for tenure and promotion as well as scholarly impact. Our results show that junior and early-career scholars are significantly more likely to have a profile than those who have been in the field for a longer period. Although our data do not allow us to

\section{Figure 4}

Proportion of Those with a Google Scholar Profile in Top 25 and Bottom 25 in Cohort

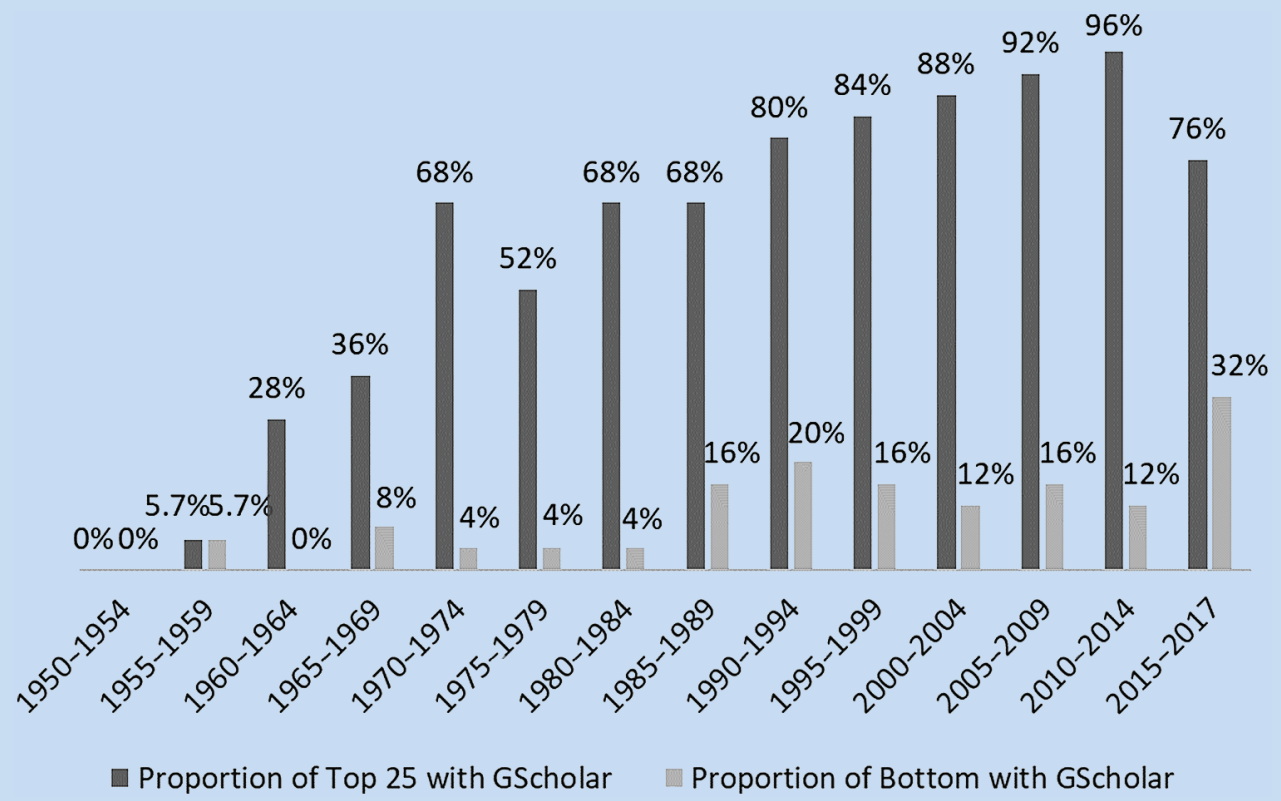


address issues of causation, one likely cause of the disparity is simply the level of familiarity with the Internet and Google Scholar. Older faculty grew up in an era when citations were counted on the Web of Science and, ceteris paribus, are less likely to be tech savvy and/or may have less interest in maintaining an does not require manual input like these alternatives. Instead, it automatically tracks a scholar's citation counts in a clear and easily accessible way and makes them available to a broader audiencewhich is incentive for those with higher citation counts to create a profile.

\section{Moreover, those who are highly cited relative to others in their cohort are more likely to have a profile than those who have fewer citation counts.}

online presence. Also, whereas most "academics are under neverending pressure to 'publish or perish"' (Jensenius et al. 2018, 821), this is especially the case for junior scholars who are working toward tenure and promotion. Moreover, whereas obtaining tenure or promotion to full professor rank has always been a difficult process, the experiences of the older of our two authors suggest that the pressure to publish has increased substantially in recent decades. Of course, greater familiarity with web and social media-based forms of communication often results in recognizing the desirability of taking advantage of these platforms-and perhaps fear of the consequences for failing to do so.

\section{Political Theorists Are Less Likely to Have a Google Scholar Profile}

According to our results, about $50 \%$ of faculty in various subfields were likely to have a Google Scholar profile. The main exception, however, was in political theory, in which only $25 \%$ had a profile. It is not especially surprising that the most quantitatively oriented political scientists-the methodologists-are most likely to have a Google Scholar profile. However, we also suspect that political theorists have the least need for a profile because they are more book oriented in terms of publications, and Google Scholar is most useful for tracking and publicizing journal articles. Theorists may have fewer items to include in a Google Scholar profile that would need to be identified by those interested in reading their most important work; thus, they have less need for a profile.?

\section{CONCLUDING REMARKS}

We believe that our results from this study can contribute useful factual information to an ongoing debate about how to evaluatefrom a more normative perspective-the increased importance of self-promotion and an online presence in the academy.

Until recently, the Social Sciences Citation Index and Web of Science were the most widely used references for research productivity. Yet, Google Scholar has risen to prominence as a measure that is transparent, easily accessible, and a relatively simple platform. Moreover, it comprehensively compiles articles, books, and manuscripts (Peress 2018). Although it has limitations and should be used with caution (Jensenius et al. 2018), it is currently the most prominent platform that allows scholars and academics to share and access information. It is much easier to identify and download the work of scholars who have a Google Scholar profile. It saves those interested in the work of an author from scrolling through numerous article and paper titles by authors with a similar name in multiple disciplines to identify the particular work or to review a CV and then search elsewhere for downloadable versions of the work.

The presence or absence of a Google Scholar profile does not affect the ability of those reviewing tenure and promotions to identify publications because CVs have been submitted. Neither should it affect the weight given publication counts or evaluations of the prestige of journals and books in which articles and chapters appear. Whether the presence or absence of a Google Scholar profile affects the incentives of those making tenure decisions to weigh citations more heavily is less clear because it does facilitate the gathering of

\section{Until recently, the Social Sciences Citation Index and Web of Science were the most widely used references for research productivity. Yet, Google Scholar has risen to prominence as a measure that is transparent, easily accessible, and a relatively simple platform.}

\section{Those with Higher Citation Counts Are More Likely to Have a Google Scholar Profile}

In almost all cohorts, those with higher citation counts are much more likely to have a Google Scholar profile. This also is an expected pattern in that, like younger and early-career faculty, those with higher citation counts may find it more desirable to gain recognition by taking advantage of platforms such as Google Scholar. A profile lists scholars' works along with their citation counts; the more someone has published, the more reason to showcase accomplishments and allow others to more easily find (and download) the work. Of course, there are other ways to display citation counts; some scholars list them on their CVs (Jensenius et al. 2018) or their website. However, Google Scholar citation information. Conversely, the presence or absence of a profile may affect how visible a scholar is in the field when soliciting external reviews. Thus, we believe that on balance, it is desirable for scholars to create a Google Scholar profile for visibility purposes. We particularly encourage younger scholars and those beginning to build a publication record to create a profile. However, we also emphasize that reliance on citation counts is particularly pernicious in the evaluation of junior scholars whose work has not yet had time to be visible to and impact the broader scholarly community.

\section{SUPPLEMENTARY MATERIALS}

To view supplementary material for this article, please visit http:// dx.doi.org/10.1017/S1049096520000189. 


\section{ACKNOWLEDGMENTS}

The authors thank the anonymous reviewers of $P S$ and the editors for their helpful feedback and comments.

\section{NOTES}

1. The KG dataset includes 132 political science $\mathrm{PhD}$-granting US institutions and total of 3,782 tenured or tenure-track faculty circa 2017 with full-time appointments in the political science department. We removed 301 scholars from the dataset of those for whom we could not find data (i.e., they did not have any articles or citation counts listed on Google Scholar). For a full description of the Kim and Grofman (2019) dataset, we refer readers to the appendix to that article. If a scholar was listed on a website as a non-emeritus tenured faculty member, KG took them to be such. Feedback subsequent to the publication of Kim and Grofman (2019) identified a few misclassified individuals in the dataset. We are working from this updated dataset; however, the changes are minor, affecting no more than zo people. The KG dataset does not include those with a $\mathrm{PhD}$ in political science but with a primary affiliation in a public-policy or law school at an R1 university. In conjunction with the APSA, the authors are seeking to remedy that limitationat least in part-via crowdsourcing and also to identify highly cited scholars whose primary affiliation is not with a political science department.

2. Of the 3,782 scholars, 3,724 are included; 58 were missing the date of $\mathrm{PhD}$

3. In table $1, \mathrm{PP}, \mathrm{PA}, \mathrm{PL}$, and PP refer to public policy, public administration, public law, and political psychology. American politics includes the subfield of race and ethnicity.

4. The observed gender difference is not statistically significant at the $p=0.05$ level Some of this difference, however, is a compositional effect because the date of $\mathrm{PhD}$ shows that female scholars, on average, are younger than male scholars. Moreover within each cohort, male scholars are more likely than female scholars to have pofile. However, those in younger cohorts are more likely to have a profile among both female and male scholars (see appendix A).

5. Cohort 1 has only 17 people and Cohort 2 has only 35 people, so we compared the top half to the bottom half. Other cohorts show the proportion from the top 25 to the bottom 25 based on citation counts.
6. Additionally, we expected those at higher-ranked institutions to be more likely to have a Google Scholar profile; contrary to our expectation, however, there were no significant differences by institutional ranking. The only stark contrast we found was that about half of the faculty at higher-ranked universities had a profile whereas $30 \%$ to $40 \%$ of those at the lowest-ranked universities had a profile showing a relatively small overall effect in the predicted direction. We used rankings from US News and World Report (see appendix B).

7. We once conjectured that the larger the subfield, the more incentive for selfpromotion via new media. However, there are too many confounding factors and the smallest group-the methodologists-had the highest use of Google Scholar profiles.

\section{REFERENCES}

Chwe, Michael, Mala Htun, Francesca R. Jensenius, Adria Lawrence, David J. Samuels, and David A. Singer. 2017. "Google Scholar in Political Science: Blessing or Curse?” Unpublished manuscript, last modified June 2017.

Jensenius, Francesca R., Mala Htun, David J. Samuels, David A. Singer, Adria Lawrence, and Michael Chwe. 2018. "The Benefits and Pitfalls of Google Scholar." PS: Political Science \& Politics 51 (4): 820-24.

Kim, Hannah June, and Bernard Grofman. 2019. "The Political Science 400: With Citation Counts by Cohort, Gender, and Subfield." PS: Political Science \& Politics 52 (2): 296-311.

Masuoka, Natalie, Bernard Grofman, and Scott Feld. 2007. "The Political Science 400: A 20-Year Update." PS: Political Science \& Politics 40 (1): 133-45.

Peress, Michael. 2018. "Measuring the Research Productivity of Political Science Departments Using Google Scholar." PS: Political Science \& Politics 52 (2): 312-17.

Samuels, David J. 2011. "The Modal Number of Citations to Political Science Articles Is Greater than Zero: Accounting for Citations in Articles and Books." PS: Political Science \& Politics 44 (4):783-92.

Samuels, David J. 2013. “Book Citation Counts.” PS: Political Science \& Politics 46 (4): 785-90. 


\section{APPENDIX}

A. PROPORTION OF THOSE WITH GS PROFILES BY 5-YEAR COHORT AND BY GENDER

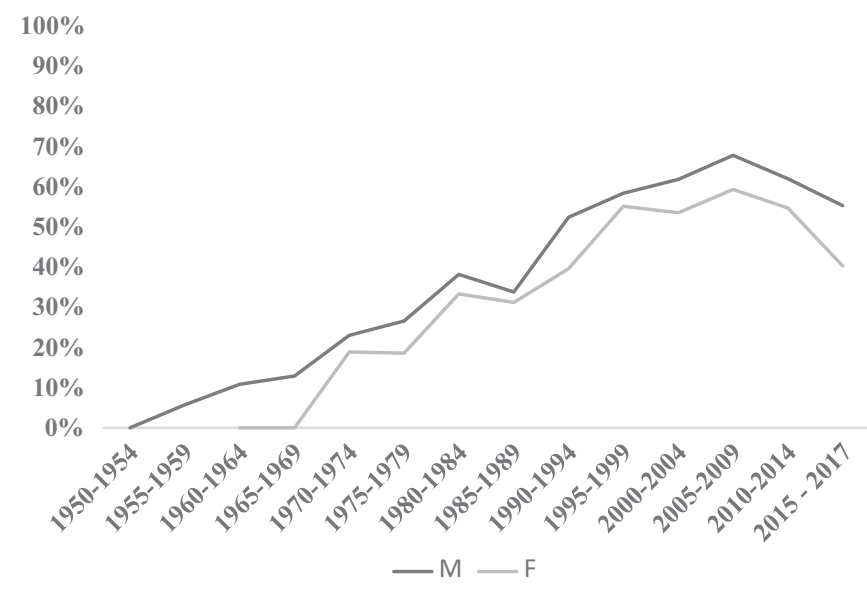

B. PROPORTION OF THOSE WITH GS PROFILES BY UNIVERSITY RANKING (IN TENS)

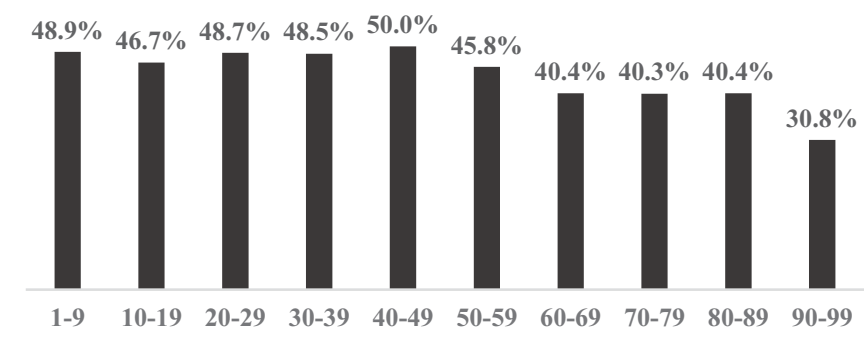

